\title{
CRYPTOSPORIDIUM: FROM LABORATORY DIAGNOSIS TO SURVEILLANCE AND OUTBREAKS
}

\author{
CHALMERS R.M.*
}

\section{Summary :}

The burden of disease caused by the protozoan parasite Cryptosporidium is unknown. However, routine laboratory diagnosis and surveillance enables the basic epidemiology to be described, changes to be monitored and under-ascertainment to be measured. Although the two main species involved in human disease in developed countries, Cryptosporidium parvum and Cryptosporidium hominis, have differing epidemiologies and risk factors, national surveillance is generally from isolates identified to the genus level only. Enhancing the data by typing, at least to identify the isolates to the species level, removes some of the noise generated and better identifies the risks than when reports are not species-specific. This level of identification is also valuable for outbreak investigations, but further investigation of the population genetics of $C$. parvum and $C$. hominis is required for the development of more readily applied subtyping tools.

KEY WORDS : Cryptosporidium, diagnosis, surveillance, outbreaks, genotyping.

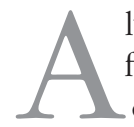
lthough the Apicomplexan Cryptosporidium was first described at the beginning of the twentieth century (Tyzzer, 1907), human disease (cryptosporidiosis) was first identified almost three quarters of a century later. Two reports were published in 1976: one based on the findings of histological examination of jejunal biopsy from a severely dehydrated immunosuppressed adult male patient with chronic watery diarrhoea (Meisel et al., 1976) and the other on exanimation of rectal biopsy from an otherwise healthy female child with watery diarrhoea, abdominal pain and vomiting (Nime et al., 1976). The first patient recovered after withdrawal of immunosuppressive treatment and subsequent restoration of T-cell count and function and the child recovered spontaneously after two weeks. In the 1970s, Cryptosporidium was beginning to be recognised as a cause of gastro-intestinal disease ("scours") in neonatal calves (Panciera et al., 1971; Pohlenz et al., 1978) and during the 1980s, awareness of the potential of this parasite to cause disease in humans increased largely as a result of the AIDS epidemic. Cryptosporidium was widely regarded as an opportunist zoonotic infection causing severe and often

\footnotetext{
* UK Cryptosporidium Reference Unit, NPHS Microbiology Swansea, Singleton Hospital, Swansea SA2 8QA, UK.

Tel.: +44 (0)1792 285341 - Fax: +44 (0)1792 202320.

E-mail: rachel.chalmers@nphs.wales.nhs.uk
}

fatal disease in AIDS patients (Ma \& Soave, 1983; Current et al., 1983), who were then mainly urban dwelling, adult male homosexuals. However, other immunocompromised patients and, conversely, otherwise healthy people, including veterinary workers and particularly veterinary students, were also diagnosed with cryptosporidiosis (Jokipii et al., 1983; Current et al., 1983). This presented an epidemiological conundrum: was the disease an opportunist; was it a zoonosis; what were the transmission routes; which other groups might be at risk? Similarly, there were diagnostic questions: had the difficulties in laboratory diagnosis led to gross under-ascertainment of this pathogen? Early epidemiological studies demonstrated an urban cycle of infection in otherwise healthy people, and confirmed the importance of day care centres and person-to-person spread (Casemore \& Jackson, 1983). The validity of the description of cryptosporidiosis solely as an opportunistic zoonosis was doubted (Casemore \& Jackson, 1984), while several independent studies during the 1980s worldwide showed cryptosporidiosis as a common cause of self-limiting gastroenteritis in otherwise healthy people, particularly children (Casemore, 1990; Palmer \& Biffin, 1990). The first outbreak which led to the recognition of Cryptosporidium as a waterborne pathogen occurred in Texas, USA in 1984, involving 79 cases with diarrhoea of which 47 were laboratory confirmed as Cryptosporidium. The public water supply, which came from a well contaminated with sewage, was the implicated vehicle (D'Antonio et al., 1985). It thus became evident that the epidemiology of cryptosporidiosis is complex, involving both direct and indirect transmission from both animals and humans, enabled by the robust nature of the transmissive stage of the parasite, the oocyst. However, microbiological evidence for the sources of infection was not possible until suitable typing methods were established. Laboratory diagnosis of cryptosporidiosis is traditionally by tinctorial or fluorescent staining of faecal smears followed by microscopical examination, or more recently by the use of copro-antigen detection kits, such as immunofluorescent antibody stains for microscopy, enzyme linked immunosorbent assays (ELISAs) or immunochromatographic tests. The analytical sensiti- 
vity of these methods is generally in excess of $10^{4}$ oocysts per gram faeces (opg), depending on faecal consistency (Anusz et al., 1990; Weber et al., 1991), although immunofluorescence microscopy offers improved sensitivity (Arrowood, 1997). The oocyst is the diagnostic target, and none of these methods is capable of differentiating Cryptosporidium species. A variety of detection methods are employed and, in addition, laboratory selection criteria for testing vary: in the UK it is recommended that all first time acute faecal samples from community cases of diarrhoea are tested for Cryptosporidium (Health Protection Agency, 2007), and there is generally good, but not total, compliance with this (Chalmers et al., 2002a). Elsewhere, laboratory testing is often restricted to AIDS patients. Surveillance strategies for Cryptosporidium also vary: in some countries the laboratory diagnosis is statutorily notifiable at a national level, for example in Ireland, Finland, Germany and Sweden, while in others data are collected on a voluntary reporting basis, for example in the UK and the Netherlands. In France there is a reporting network of sentinel laboratories. Differences also occur locally (Chalmers et al., 2002a), but voluntary reporting in the UK is widespread and goes back to 1983. Between 1983 and 1989 reporting increased as laboratory testing became more common, and since 1990 reports to the Health Protection Agency's Centre for Infection (CfI) show a mean annual incidence of 8.9 cases per 100000 population, with all ages affected but most reported in children under five years (Nichols et al., 2006a). There is an annual bimodal distribution with peaks in the spring and autumn, but since 2001 there has been an overall reduction in the number of reports in the first part of the year, linked to the beneficial impact of The Water Supply (Water Quality) (Amendment) Regulations 1999 (Sopwith et al., 2005; Lake et al., 2007). The risk factors for cases in the second half of the year are unclear but may be linked to travel and recreational water use. The total disease burden from Cryptosporidium is unknown: a study of infectious intestinal disease in England in 1995 suggested that, when traditional diagnostic methods are used, one in every 7.4 cases are diagnosed and reported (Adak et al., 2002). Further infections would be identified by the use of more sensitive diagnostic tests, such as PCR-based methods (Amar et al., 2007).

These national variations in laboratory testing and surveillance strategies will have an impact on the number of cases and indeed outbreaks identified as those recognized in one country might be missed elsewhere. This is illustrated well in a review of cryptosporidiosis surveillance and waterborne outbreaks in Europe (Semenza \& Nichols, 2007) where cryptosporidiosis is notifiable at European Union level. Over $70 \%$ of reports were from the UK, reflecting the high degree of laboratory testing and reporting, and the highest incidence was in Ireland where cryptosporidium was made a reportable diagnosis in 2004. Reports may also be collected as part of surveillance for acute gastroenteritis linked to food poisoning or for outbreaks. For example, in the USA a voluntary national outbreak surveillance system began in 1971, and initially included drinking waterborne outbreaks, expanded in 1978 to include recreational water outbreaks and in 1999 those related to water not intended for drinking, exposures in occupational settings and commercially bottled water. The system is continually updated and the most recent summary, covering the period 2002 to 2003, also includes outbreaks linked to contaminated ice and beverages, drinks machines and water at the point of use (Anon, 2006; Yoder et al., 2007).

Structured surveillance for outbreaks of gastro-intestinal disease has been undertaken in England and Wales since 1992 (Wall et al., 1996), and indicates that about $10 \%$ of reported cases of cryptosporidiosis are part of identified outbreaks (Nichols et al., 2006a). Between 1983 (when surveillance for Cryptosporidium began) and 2005, a total of 151 Cryptosporidium outbreaks involving 9893 cases illness were reported to CfI, involving many vehicles for infection, including public water supplies (56 outbreaks), private water supplies (6), swimming pools (44), other recreational waters (7), animal contact and farms (19), food (4), person-to-person spread (10) and unknown (5). Cryptosporidium clearly plays a particular role in waterborne disease, facilitated by many inherent biological features, reported elsewhere (Karanis et al., 2007). In a review of 89 outbreaks of waterborne disease involving 4,321 cases in England and Wales (Smith et al., 2006), Cryptosporidium was the causative agent in $69 \%$. The strength of association with water is measured by the robustness of epidemiological and environmental evidence (Tillet et al., 1998), although the contamination event may be missed in terms of sampling by the time an outbreak is recognised. This is particularly important for the investigation of Cryptosporidium where the incubation period between exposure and the development of symptoms is long (up to two weeks) and the interpretation of indicator data (microbial and water treatment process data, including turbidity) requires careful interpretation. Additionally, sampling for and laboratory identification of waterborne pathogens is difficult, particularly for Cryptosporidium. In an analysis of public supply outbreaks in the USA, an aetiological agent was not determined in $41 \%$ (Craun et al., 2002). Even where continual monitoring for Cryptosporidium is in place, as it has been at some water treatment plants in the UK for nearly a decade, interpretation of the results is complex: outbreaks have occurred where low numbers of oocysts have been detected (Anon, 2006), and high numbers of oocysts do not necessarily lead to increased disease (Hunter et al., 2000). This is because the dynamics of an outbreak are multi-factorial, and the 
behaviour and herd-immunity of the exposed population and the infectivity of the oocysts for man are both important.

Human disease has been traditionally attributed to Cryptosporidium parvum but it was apparent from both the early epidemiological questions raised regarding the zoonotic status and transmission of the organism that variants occurred. Animal infectivity studies in the 1980s demonstrated that infective dose sizes and clinical responses varied between isolates (Fayer \& Ungar, 1986; Pozio et al., 1992) and human infectivity studies have demonstrated differences in $\mathrm{ID}_{50}$, attack rate, pre-patent period, duration of disease, and frequency of stools between three different $C$. parvum isolates (IOWA, TAMU and UCP) (Okhuysen et al., 1999). Phenotypic analysis focussing on protein, antigenic and isoenzyme diversity showed that differences were consistent with other biological and/or epidemiological data and "animal types" and "human types" were suggested by McDonald and Awad-el-Kariem in 1995. The limitation of these phenotypic methods was the huge numbers of oocysts required, which hampered their widespread use. Analysis of the C. parvum genome at a repetitive DNA sequence showed genetic heterogeneity within the species (Ortega et al., 1991) but also required enormous numbers of oocysts. It was the amplification provided by PCR that facilitated further exploration of differences at the genomic level (Laxer et al., 1991). Throughout the 1990s genetic analysis of human isolates consistently identified two distinct C. parvum types, one variously referred to as the "cattle" genotype, genotype 2 or $\mathrm{C}$ and the other as the "human" genotype, genotype 1 or $\mathrm{H}$. In 2002, Morgan-Ryan et al. proposed that the "human" genotype was a separate species, Cryptosporidium hominis $\mathrm{n}$. sp., on the basis of evidence conforming to criteria shown below. At the time of writing, 16 Cryptosporidium species are currently recognised, defined according to the criteria agreed at the $6^{\text {th }}$ Meeting on Molecular Epidemiology and Evolutionary Genetics in Infectious Disease in Paris, France (Xiao et al., 2004): C. parvum, C. hominis, C. felis, C. canis, C. wrairi, C. varani, C. suis, C. bovis, C. andersoni, C. muris, C. serpentis, C. galli, C. meleagridis, C. fayeri, C. macropodum and C. baileyi. The four basic requirements for the naming of Cryptosporidium species are: 1. Morphometric study of oocysts and, if possible, sporozoites.

2. Multi-locus genetic characterisation by nucleotide sequence analysis of well studied genes or non-coding regions. The ssu rRNA gene is usually included.

3. Demonstration of natural and, if possible, experimental, host specificity.

4. Compliance with the International Code of Zoonotic Nomenclature.

Analysis of the ssu rRNA gene by DNA sequence analysis is regarded as the benchmark against which iden- tifications made at alternative loci can be compared. The advantages of the ssu rRNA gene are two-fold. First, it is sufficiently conserved so that primers are available that amplify all known species and "genotypes", yet it contains a highly variable central region at which these can be differentiated (Xiao et al., 1999). Secondly, there are five copies of the gene in each Cryptosporidium sporozoite genome, and with four sporozoites in every intact oocyst, there are twenty copies present (Le Blancq et al., 1997), potentially providing greater sensitivity than assays targetting single-copy genes. However, variation within multicopy genes may present an analytical challenge. Sulaiman and colleagues (1999) compared the analytical sensitivity of 11 genotyping techniques and identified that improved specificity of primer pairs and nested PCR protocols improved sensitivity over single round PCR. In an inter-laboratory comparative study of typing methods for species identification from clinical isolates, results from ssu rRNA and COWP PCR-RFLP were mutually supporting (Chalmers et al., 2005).

The value of typing Cryptosporidium isolates from routine diagnosis to the species level has been demonstrated in special studies, establishing the range of species involved in human disease, their differing epidemiology and risk factors. Eight species are known to be infectious for man: C. parvum, C. hominis, C. meleagridis, C.felis, C. canis, C. suis, C. muris and C. andersoni, although some are reported extremely rarely, particularly the latter three species, and the pathogenicity of some species for man has not been proven. In the UK, $96 \%$ of 13,112 isolates collected since 1989 from patients with diarrhoea are either C.parvum or C. hominis (Nichols et al., 2006a), and other species are not restricted to immunocompromised patients (Chalmers et al., 2002b). In developing countries other species are more common and occur in both HIV positive and negative people (Xiao et al., 2001; Gatei et al., 2002, Cama et al, 2003).

Long-term molecular surveillance has shown differences in the distribution of species by person, time and place in the UK (Anon, 2002; McLauchlin et al., 2000; Leoni et al., 2006, Nichols et al., 2006a) and the epidemiological "noise" is reduced when typing results are incorporated into routine surveillance, as is current in Scotland (Chalmers \& Pollock, 2007). Changes in the epidemiology are more readily observed and investigated (Smerdon et al., 2003; Hunter et al., 2003; Sopwith et al., 2005). Analytical epidemiological studies have identified specific risk factors for sporadic cases: contact with farmed animals for C. parvum and travel abroad, changing nappies and contact with another infected person for C. hominis (Hunter et al., 2004a) and linked species to socio-economic factors (Lake et al., 2007). Species identification is an important element of outbreak investigations particularly where the source 
is not clear (Glaberman et al., 2002), and it is important that this is underpinned by routine species identification to establish the background epidemiology. The infecting species has been identified in a large number of outbreaks worldwide, and C. parvum and/or C. hominis are always involved (Smith et al., 2006; Nichols et al., 2006a). This level of characterisation is also valuable in assessing public health risk when oocysts are detected in treated water, since the oocyst count may comprise species which pose a low risk to public health (Nichols et al., 2006b).

Further characterisation of Cryptosporidium oocysts from both patients and suspected sources and vehicles of transmission is an important investigative tool during outbreaks. Not only have potential sources been better defined, for example identifying human sewage as the potential contaminant over agricultural pollution (Glaberman et al., 2002) but also the relationship between source, supply and human cases and isolates circulating in the community in general (Zhou et al., 2003; Cohen et al., 2006; Anon 2006; Chalmers et al., 2008). However, Cryptosporidium presents three main problems for the isolation of DNA: 1) the robust nature of the oocysts, requiring a disruption step prior to DNA extraction; 2) the richness of PCR inhibitors in the sample matrix, requiring separation during DNA extraction and/or suppression during amplification; and 3) the low number of oocysts usually present in prospectively gathered and environmental samples. Numerous methods have been used for the extraction of Cryptosporidium DNA, but an optimised reliable standard method is lacking and is particularly desirable for samples where small numbers of oocysts may be present (Jiang et al., 2005). Appropriate PCR primer design and choice of target locus is required to avoid bias in both amplification and interpretation of results. Catchment-based studies have shown that environmental samples are likely to contain multiple species (Robinson, 2005) and repetitive PCR improves detection of these (Ruecker et al., 2005). There is currently no international consensus of typing methods, and many rely on DNA sequence analysis which can be time-consuming and costly.

Not only have epidemiological differences and risk factors been identified by typing but also clinical manifestations, which vary between $C$. parvum and C. hominis (Hunter et al., 2004b; Bushen et al., 2007) and between subtypes (Cama et al., 2007). Subtyping is essential to explore these and other differences in the species diversity and descriptive and analytical epidemiology which appear to vary geographically and with socioeconomic groups. However, more information is required about the population genetics of Cryptosporidium species, which appear to be geographically linked, and distribution influenced by exposure and soci-economic factors (Mallon et al., 2003; Gatei et al., 2007, Hunter et al., 2007, Chalmers et al., 2008).
Typing methods have been compared in an initial study, the analysis of single strand conformation polymorphisms (SSCP) demonstrated that rapid methods are worth pursuing (Chalmers et al., 2005). A systematic review of the literature (Robinson, 2005) has shown that none of the typing methods applied to Cryptosporidium have been systematically evaluated, based on principles of internationally accepted methods for evaluation of microbial typing schemes (Struelens et al., 1996). Standardisation of methods and nomenclature is desirable and should be promoted.

The importance of characterisation of Cryptosporidium isolates to species level and of subtyping is undoubted, but future developments need to include harmonisation of rapid and more cost effective methods if these are to be adopted outside specialist laboratories and for investigation in real-time to provide information for appropriate control measures during outbreaks.

\section{REFERENCES}

AdAK G.K., LONG S.M. \& O'Brien S.J. Trends in indigenous foodborne disease and deaths, England and Wales: 19922000. Gut, 2002, 51, 832-841.

Amar C.F.L., East C. L., Gray J., Iturriza-Gomara M., Maclure E.A. \& MCLAuChlin J. Detection by PCR of eight groups of enteric pathogens in 4,627 faecal simples: re-examination of the English case-control Infectious Intestinal Disease Study (1993-1996). European Journal of Clinical Microbiology and Infectious Disease, 2007, 26, 311-323.

ANON. Surveillance for Waterborne Disease and Outbreaks associated with Recreational Water - United States 20032004, and Surveillance for Waterborne Disease and Outbreaks associated with Drinking Water and Water not intended for Drinking - United States 2003-2004. Morbidity and Mortaility Weekly Report - Surveillance Summary, 2006, 55, SS-12.

ANON. The development of a national collection for oocysts of Cryptosporidium. Final report to DEFRA: Drinking Water Inspectorate, 2002. Foundation for Water Research, Marlow, Bucks, UK. Available from http://www.fwr.org/

Anusz K.Z., Mason P.H., Riggs M.W. \& Perryman L.E. Detection of Cryptosporidium parvum oocysts in bovine feces by monoclonal antibody capture enzyme-linked immunosorbent assay. Journal of Clinical Microbiology 1990, 28, 2770-2774.

Arrowood M.J. Diagnosis, in Cryptosporidium and cryptosporidiosis. Fayer R. (ed.), CRC Press, Boca Ratton, 1997, 43-64.

Bushen O.Y., Kohli A., Pinkerton R.C. Newman R, Fayer R, Alima A \& Guerrant M. Heavy cryptosporidial infections in children in northeast Brazil: comparison of Cryptosporidium hominis and Cryptosporidium parum. Transactions of the Royal Society for Tropical Medicine and Hygiene, 2007, 101, 378-384

Cama V.A., Bern C., Sulaiman I.M., Gilman R.H., Ticona E., Vivar A., Kawai V., Vargas D., Zhou L. \& XiaO L. Crypto- 
sporidium species and genotypes in HIV-positive patients in Lima, Peru. Journal for Eukaryotic Microbiology, 2003, 30 (Suppl.), 531-533.

Cama V.A., Ross J.M., Crawford S., Kawai V., Chavez-Valdez R., Vargas D., Vivar A., Ticona E., Navincopa M., Williamson J., Ortega Y., Gilman RH., Bern C. \& Xiao L. Differences in clinical manifestations among Cryptosporidium species and subtypes to HIV-infected persons. Journal of infectious Diseases, 2007, 196, 684-691.

Casemore D.P. \& Jackson F.B. Hypothesis: cryptosporidiosis in humans is not primarily a zoonosis. Journal of Infection, 1984, 9, 153-156.

Casemore D.P. \& Jackson F.B. Sporadic cryptosporidiosis in children. The Lancet, 1983, ii, 679.

CASEmore D.P. Epidemiological aspects of human cryptosporidiosis. Epidemiology and Infection, 1990, 104, 1-28.

Chalmers R.M., Hadfield S.J., Jackson C.J., Elwin K., Xiao L. \& Hunter P. Variation in Cryptosporidium hominis is geographically linked. Emerging Infectious Diseases, 2008, 14, 496-498.

Chalmers R.M., Elwin K, Thomas A. \& Joynson D.H.M. Unusual types of cryptosporidia are not restricted to immunocompromised patients. Journal of Infectious Diseases, 2002b, 185, 270-271.

Chalmers R.M. \& Pollock K.G.J. Cryptosporidium in Scotland 2006: reference laboratory data. HPS Weekly Report [serial online] 2007 [cited October 2007] 41, 2007/36, 301-303. Available online at http://www.hps.scot.nhs.uk/

Chalmers R.M., Hughes S., Thomas A.L., Woodhouse S., Thomas P.D. \& HunTeR P. Laboratory ascertainment of Cryptosporidium and local authority public health policies for the investigation of sporadic cases of cryptosporidiosis in two regions of the United Kingdom. Communicable Disease and Public Health, 2002a, 5, 114-118.

Chalmers R.M., Ferguson C., Cacciò S.M., Gasser R.B., El-Osta Y.G.A., Heijnen L., Xiao L., Elwin K., Hadfield S., Sinclair M. \& STEvens M. Direct comparison of selected methods for genetic categorization of Cryptosporidium parvum and Cryptosporidium hominis. International Journal for Parasitology, 2005, 35, 397-410.

Cohen S., Dalle F., Gallay A., Di Palma M., Bonnin A. \& Ward H.D. Identification of Cpgp40/15 Type Ib as the predominant allele in isolates of Cryptosporidium spp. from a waterborne outbreak of gastroenteritis in South Burgundy, France. Journal of Clinical Microbiology, 2006, 44, 589-591.

Communicable Disease Report Weekly [serial online] 2006 [cited October 2007] 16 (28) 11-13 Available at http:// www.hpa.org.uk/cdr/archives/2006/cdr2806.pdf

Craun G.F., Nwachuku N., Calderon R.L. \& Craun M.F. Outbreaks in drinking-water systems, 1991-1998. Journal of Environmental Health, 2002, 65 (1), 16-23.

Current W.L., Reese N.C., Ernst J.V., Bailey W.S., Heyman M.B. \& Weinstein W.M. Human cryptosporidiosis in immunocompetent and immunodeficient persons. Studies of an outbreak and experimental transmission. New England Journal of Medicine, 1983, 308, 1252-1257.

D’Antonio R.G., Winn R.E., Taylor J.P., Gustafson T.L., CurRent W.L., Rhodes M.M., Gary G.W. JR. \& Zajac R.A. A waterborne outbreak of cryptosporidiosis in normal hosts. Annals of Internal Medicine, 1985, 103, 886-888.

FAYER R. \& Ungar B.L. Cryptosporidium spp. and cryptosporidiosis. Microbiology Review, 1986, 50, 458-483.

Gatei W., Ashford R.W., Beeching N.J., Kang'ethe Kamwati S., Greensill J. \& HaRt C.A. Cryptosporidium muris infection in an HIV-infected adult, Kenya. Emerging Infectious Diseases, 2002, 8, 204-206.

Gatei W., Das P., Dutta P., Sen A., Cama V., Lal A.A. \& Xiao L. Multilocus sequence typing and genetic structure of Cryptosporidium hominis from children in Kolkata, India. Infection, Genetics and Evolution, 2007, 7,197-205.

Glaberman S., Moore J.E., Lowery C.J., Chalmers R.M., Sulaiman I., Elwin K., Rooney P.J., Millar B.C., Dooley J.S.G., LAL A.A. \& XIAO L. Three drinking-water-associated cryptosporidiosis outbreaks, Northern Ireland. Emerging Infectious Diseases, 2002, 8, 631-633.

Health Protection Agency. Investigation of specimens other than blood for parasites. National Standard Method BSOP 31. London 2007. Available at http://www.hpa.org.uk

HunTER P.R. \& THE WORKING GROUP. Advice on the response from public and environmental health to the detection of cryptosporidial oocysts in treated drinking water. Communicable Disease and Public Health, 2000, 3 (1), 24-27.

Hunter P.R., Chalmers R.M., Syed Q., Hughes S.L., WoOdhouse S. $\&$ SWIFT L. Foot and mouth disease and cryptosporidiosis: possible interaction between two emerging infectious diseases. Emerging Infectious Diseases, 2003, 9, 204206.

Hunter P.R., Hadfield S.J., Wilkinson D., Lake I.R., Harrison F.C.D. \& Chalmers R.M. Subtypes of Cryptosporidium parvum in humans and disease risk. Emerging Infectious Diseases, 2007, 13, 82-88.

Hunter P.R., Hughes S., Woodhouse S., Raj N., Syed Q., ChalMERS R.M., Verlander N.Q. \& GoOdacre J. Health sequelae of human cryptosporidiosis in immunocompetent patients. Clinical Infectious Diseases, 2004b, 39, 504-510.

Hunter P.R., Hughes S., Woodhouse S., Syed Q., Verlander N.Q., Chalmers R.M., Morgan K., Nichols G., Beeching N. \& OsBorn K. Sporadic cryptosporidiosis case-control study with genotyping. Emerging Infectious Diseases, 2004a, 10 (7), 1241-1249.

Jiang J., Alderisio K.A., Singh A. \& Xiao L. Development of procedures for direct extraction of Cryptosporidium DNA from water concentrates and for relief of PCR inhibitors. Applied and Environmental Microbiology, 2005, 71 (3), 1135-1141.

Jokipil L., Pohjola S. \& JokIPII A.M. Cryptosporidium: a frequent finding in patients with gastrointestinal symptoms. Lancet, 1983, 322, 358-361.

Karanis P., Kourenti C. \& SMITH H. Waterborne transmission of prozoan parasites: a worldwide review of outbreaks and lessons learnt. Journal of Water and Health, 2007, 5 (1), 1-38.

LaKe I.R., Harrison F.C.D, Chalmers R.M, Bentham G., Nichols G., Hunter P.R., Kovats R.S. \& Grundy C. Case-control study of environmental and social factors influencing cryptosporidiosis. European Journal of Epidemiology, 2007, 22, (11), 805-811. 
Lake I.R., Nichols G., Bentham G., Harrison F.C., Hunter P.R. \& Kovats S.R. Cryptosporidiosis decline after regulation, England and Wales, 1989-2005. Emerging Infectious Disease, 2007, 13 (4), 623-625.

LaXer M.A., Timblin B.K. \& Patel R.J. DNA sequencing for the specific detection of Cryptosporidium parvum by the Polymerase Chain Reaction. American Journal of Tropical Medicine and Hygiene, 1991, 45 (6), 688-694.

Le Blance S.M., Khramtsov N.V., Zamani F., Upton S.J. \& Wu T.W. Ribosomal RNA gene organisation in Cryptosporidium parvum. Molecular and Biochemical Parasitology, 1997, 90, 463-478.

Ma P. \& SOAvE R. Three-step stool examination for cryptosporidiosis in 10 homosexual men with protracted watery diarrhea. Journal of Infectious Diseases, 1983, 147, 824-828.

Mallon M.E., Macleod A., Wastuing J.M., Smith H. \& TAit A. Multilocus genotyping of Cryptosporidium parvum type 2: population genetics and sub-structuring. Infection, Genetics and Evolution, 2003, 3, 207-218.

McDonald V. \& Awad el Kariem. Strain variation in Cryptosporidium parvum and evidence for distinctive human and animal strains, in: Protozoan Parasites and Water. The Royal Society of Chemistry, Cambridge, 1995, 104-107.

Mclauchlin J., Amar C., Pedraza-Di’az S. \& Nichols G.L. Molecular epidemiological analysis of Cryptosporidium spp. in the United Kingdom: results of genotyping Cryptosporidium spp. in 1,705 fecal samples from humans and 105 fecal samples from livestock animals. Journal of Clinical Microbiology, 2008, 38, 3984-3990.

Meisel J.L., Perera D.R., Meligro C. \& Rubin C.E. Overwhelming watery diarrhea associated with a Cryptosporidium in an immunosuppressed patient. Gastroenterology, 1976, $70,1156-1160$

Morgan-Ryan U.M., Fall A., Ward L.A., HijJawi N., Sulaiman I., Fayer R., Thompson RCA., Olson M., Lal A. \& Xiao L. Cryptosporidium hominis n. sp. (Apicomplexa: Cryptosporidiidae) from Homo sapiens. The Journal of Eukaryotic Microbiology, 2002, 49 (6), 433-440.

Nichols G., Chalmers R., Lake I., Sopwith W., Regan M., Hunter PR., Grenfell P., Harrison F. \& Lane C. Cryptosporidiosis: a report on the surveillance and epidemiology of Cryptosporidium infection in England and Wales. Foundation for Water Research, Marlow, Bucks, UK, 2006 a. Available from http://www.fwr.org/

Nichols R.A.B., CAmpbell B.M. \& SMiTh H.V. Molecular fingerprinting of Cryptosporidium species oocysts isolated during water monitoring. Applied and Environmental Microbiology, 2006b, 72 (8), 5428-5435.

Nime F.A., Burek J.D., Page D.L. \& Yardlet J.H. Acute enterocolitis in a human being infected with the protozoan Cryptosporidium. Gastroenterology, 1976, 10.

Ortega Y.R., Sheehy R.R., CAma V.A., Oishi K.K. \& Sterling C.R. Restriction fragment length polymorphism analysis of Cryptosporidium parvum isolates of bovine and human origin. Journal of Protozoology, 1991, 38 (6), 40S-41S.

Okhuysen P.C., Chappell C.L., CrabB J.H., Sterling C.R. \& DuPonT H.L. Virulence of three distinct Cryptosporidium parvum isolates from healthy adults. Journal of Infectious Diseases, 1999, 180, 1275-1281.
Palmer S.R. \& Biffin A.H. Cryptosporidiosis in England and Wales: prevalence and clinical and epidemiological features. British Medical Journal, 1990, 300, 774-777.

Panciera R.J., Thomassen R.W. \& Garner F.M. Cryptosporidial infection in a calf. Veterinary Pathology, 1971, 8, 479-484.

Pohlenz J., Moon H.W., Cheville N.F. \& Bemrick W.J. Cryptosporidiosis as a probable factor in neonatal diarrhea of calves. Journal of the AmericanVeterinary Medical Association, 1978, 172, 452-457.

Pozio E., Gomez Morales M.A., Barbicri F.M. \& LaRosa G. Cryptosporidium: different behaviour in calves of isolates of human origin. Transactions of the Royal Society for Tropical Medicine and Hygiene, 1992, 86, 636-638.

Robinson G. PhD Thesis. The investigation of the health significance of protozoan parasites in the environment. University of Wales College of Medicine, Cardiff, 2005.

Ruecker N.J, Bounsombath N., Wallis P., Ong C.S.L, IsaacRenton J.L. \& Neumann N.F. Molecular Forensic Profiling of Cryptosporidium Species and Genotypes. Raw Water Applied and Environmental Microbiology, 2005, 12, 89918994.

Semenza J. \& Nichols G. Cryptosporidiosis surveillance and water-borne outbreaks in Europe. Euro Surveill. 2007; 12 (5) [Epub ahead of print]. Available online: http://www.eurosurveillance.org/em/v12n05/1205-227.asp

Smerdon W.J., Nichols T., Chalmers R.M., Heine H. \& ReaCHER M. Decrease in human cryptosporidiosis coincident with the Foot and Mouth Disease epidemic: a measure of the livestock attributable fraction in England and Wales? Emerging Infectious Diseases, 2003, 9, 22-28.

Smith A., Reacher M., Smerdon W., Adak G.K., Nichols G. \& Chalmers R.M. Outbreaks of Waterborne Infectious Intestinal Disease in England and Wales, 1992-2003. Epidemiology and Infection, 2006, 134, 1141-1149.

Smith H.V., Caccio S.M., Tait A., Mclauchlin J. \& Thompson R.C.A. Tools for investigating the environmental transmission of Cryptosporidium and Giardia infections in humans. Trends in Parasitology, 2006, 22 (4), 160-167.

Sopwith W., Osborn K., Chalmers R. \& Regan M. The changing epidemiology of cryptosporidiosis in North West England. Epidemiology and Infection, 2005, 133, 785-793.

Struelens M.J. \& the Members of the European Study Group on Epidemiological Markers (ESGEM) of the European Society for Clinical Microbiology and Infectious Diseases (ESCMID). Consensus guidelines for appropriate use and evaluation of microbial epidemiologic typing systems. Clinical Microbiology and Infection, 1996, 2, 2-11.

Sullaiman I.M., XIAO L. \& Lal A. Evaluation of Cryptosporidium parvum genotyping techniques. Applied and Environmental Microbiology, 1999, 65 (10), 4431-4435

Tillet H.E., DE Louvois J. \& Wall P.G. Surveillance of outbreaks of waterborne disease: categorizing levels of evidence. Epidemiology and Infection, 1998, 120 (1), 37-42.

Tyzzer E.E. A sporozoan found in the peptic glands of the common mouse. Proceedings of the Society for Experimental Biology and Medicine, 1907, 5, 12-13.

Wall PG., De Louvois J., GilberT RJ. \& Rowe B. Food poisoning notifications, and outbreaks - where do the statistics 
come from and what do they mean? Communicable Disease Report CDR Weekly, 1996, 6, R93-R100

Weber R., Bryan R.T., Bishop H.S., Walquist S.P., Sullivan J.J. \& JURANEK D.D. Threshold of detection of Cryptosporidium oocysts in human stool specimens: evidence for low sensitivity of current methods. Journal of Clinical Microbiology, 1991, 29, 1323-1327.

Xiao L., Escalante L., Yang C., Sulaiman I., Escalante A.A., Montali R.J., Fayer R. \& Lal A.A. Phylogenetic analysis of Cryptosporidium parasites based on the small-subunit rRNA gene locus. Applied and Environmental Microbiology, 1999, 65, 1578-1583.

Xiao L., Bern C., Limor J., Sulaiman I., Roberts J., Checkley W. Cabrera L. Gilman R.H. \& Lal A.A. Identification of five types of Cryptosporidium parasites in children in Lima, Peru. Journal of Infectious Diseases, 2001, 183, 492-497.

XiaO L., Fayer R., Ryan U. \& Upton S.J. Cryptosporidium taxonomy: recent advances and implications for public health. Clinical Microbiology Reviews, 2004, 17 (1), 72-97.

Yoder J.S. \& Beach M.J. Centers for Disease Control and Prevention (CDC). Cryptosporidiosis surveillance-United States, 2003-2005. MMWR Surveill. Summ., 2007, 56 (7), 110 .

Zhou L., Singh A., Jiang J. \& XiaO L. Molecular Surveillance of Cryptosporidium spp. in Raw Wastewater in Milwaukee: Implications for understanding outbreak occurrence and transmission dynamics. Journal of Clinical Microbiology, 2003, 41 (11), 5254-5257. 